\title{
The Role of Work-Based Learning in Building Employability Skills of Vocational Education Students
}

\author{
Kokom Komariah \\ Department Food and Fashion Education, Yogyakarta State University \\ Yogyakarta, INDONESIA \\ kokom99@yahoo.co.id
}

\begin{abstract}
The incompatibility between educational outcomes with the need of workforce is predicted due to the mismatch of workforce needs with the qualifications of produced graduates. Therefore, the learning in vocational programs must be able to give the solution. Work-Based Learning (WBL) is one of the learning in vocational education proved greatly effective to build the students' employability skills. The purposes of this writing are: (1) to reveal the importance of WBL in vocational education, (2) The effectiveness of WBL in building the employability skills of vocational education students in culinary department. Work-based learning models that used in this study is the model with the context of WBL Food Processing developed by Kokom Komariah (2013). The method used to see the effectiveness of the model with the observation sheet . The subject of this research consist of 40 students. Data were analyzed using descriptive quantitative. WBL is a bridge between the worlds of education and work. Buildable aspects of employability skills for vocational education students are dependability of working, the ability to cooperate, making judgments, initiative, interest, independence, politeness, discipline, and the ability to react to criticisms and suggestions. Therefore, WBL is a suitable learning or training method to produce excellent, skilled, and well-prepared workforces.
\end{abstract}

Index Terms - work-based learning, employability skills

\section{Introduction}

One of the future challenge of Indonesians is the improvement of competitiveness and excellence in all industrial and services sectors. The competitive value mentioned is needed to build the national competitiveness and the resilience of society's economy.

When AFTA (ASEAN Free Trade Area) and AFLA (ASEAN Free Labour Area) are in effect, Indonesia is quite struggling to compete with neighbouring countries, such as Singapore, Malaysia, and Thailand. Indonesian workforces are mostly positioned in low-level works, while expert positions from technicians to managers are mostly filled by workforces from Singapore, Philipphines, and India. This is possible due to the lack of skilled and qualified workforces, one of which is caused by educational processes and outcomes not synchronized with the need of the world of work.

It has been agreed that vocational education must be developed with the orientation of the need of workforces. Thereby, Indonesian vocational education must be able to improve the vocational abilities through trainings with the correct method so it can produce qualified and skilled workforces. Skilled workforces have important role in industrial and services sectors because they determine the quality and expenses of productions so they aid the industrialization growth of a country [1] .
Industrial world demands professionalism, working correctly, quickly, and efficiently, values time, and independent of surveillance. This professionalism will be formed by the environment and educational system, particularly the learning form and system. As known, the population of Indonesians in $2009-2010$ is 234,181,000 people, with poor people percentage of $17.75 \%$, and a group of unemployment of 15-24 years old of 5,031,017 people.

Numerous problems are still met on the field, such as numerous vocational education graduates who haven't got an employment immediately after graduation, the graduates working not on their field, or working with lower qualifications. This incompatibility between educational outcomes with the workforce needs is predicted due to the mismatch of workforce need with the graduates qualification produced. This discrepancy cannot be seen only from curriculum relevance aspect alone, but more further, which is the learning and teaching process, means and infrastructures, educator's competence or industrial practice experience. The world of work determines the workforce competence by looking at the work result quality and the level of working productivity. The reluctance of world of work to accept the educational outcomes becomes a great loss for educational world.

This condition, if left alone, will cause a great inefficiency, be it from the aspect of time, cost, and other resources. This is certainly a loss for all parties, be it for educational world as the producer of workforces, or for the world of work as the user of workforces. Therefore, a comprehensive study is need to analyze the root of the problem in order to find the solution.

Although vocational education has shown positive roles, the reality is that currently Diploma education hasn't been handled optimally, especially from the process standards. The learnings are still done conventionally, the collaboration and participation with working and industrial worlds and society is still lacking so this problem affects the quality of graduates.

In order to be able to compete in global market, vocational education graduates must be able to adopt values applied in working. These values are oftenly called "employability skills", which are non-technical skills and competence that contributes importantly for the effectiveness and success of someone in the working place.

Forming employability skills is not an easy task. A conventional learning that is characterized by transfer of knowledge and simulations will not be able to change the behavior into the ones needed by the world of work. Therefore, the learning that allows the students to 
experience the real situation such as WBL is hoped to be able to form the desired attitudes or characters.

Based on these, this writing will study the importance of WBL in vocational education, and its effectiveness in building the employability skills of vocational education student in culinary department. The information provided is hopefully able to serve as suggestions for the improvement of vocational education learning processes in the future.

\section{Method}

Work-based learning models that used in this study is the model with the context of WBL Food Processing developed by Kokom Komariah [3]. The method used to see the effectiveness of the model with the observation sheet which includes the ability employability skills, the reliability of the work dependenability, cooperative, udgment, initiative, independence, courtesy, discipline and ability to reac to suggestion. The subject of this research consist of 40 students. Data were analyzed using descriptive quantitative.

\section{Result and Discussion}

\section{a. Work-Based Learning and Its Effectiveness in Building Employability Skills}

Work-based learning is a new concept that has been developed in several countries. Its application in Indonesia certainly needs some adjustments. WBL concept unites theory and practice, knowledge and experience. This concept introduces us that the working place offers many learning opportunities.

One of the benefits of learning at the workplace is that we don't need to design a special training, which would consume a high cost. Instead, we simply need to reflect with other members about the problem being faced. [2] This method is considered as one of the success key for someone to compete in this 21 st century.

Learning in WBL context is an active engagement process which is tied to experience. This is similar to the explanation made by Medhat [5] who states that:

"Learning is a process of active engagement with experience. It is what people do when they want to make sense of the world. It may involve an increase in skills, knowledge or understanding, a deepening of values of the capacity to reflect. Effective learning will lead to change, development and a desire to learn more."

WBL process will be done through experential learning approach.[3] In the meaning of how to interpret an experience so it could become a learning. Experiential learning is a learning process which uses experience as the learning medium. Through experential learning, the culture of industrial and business world will cover the hard and soft skill aspects. Hard skills aspect is linked to the technical competence, while soft skill aspect is linked to about value systems and behaviors.

WBL has many forms and strategies in its applications. Cunningham, Dawes, and Bennett [2] identified the strategy for WBL and its development, including action learning, apprenticeship, career advice, continuing professional development, internship, mentoring, networks and communities, qualifications, self-managed learning and team development. The variability of WBL starts from merely bringing in a guest lecturer, doing interviews, tour to industries, on-the-job training, to competitive employment. These are the levels of involvement of world of work against the educational institutions. These levels can be illustrated like this:

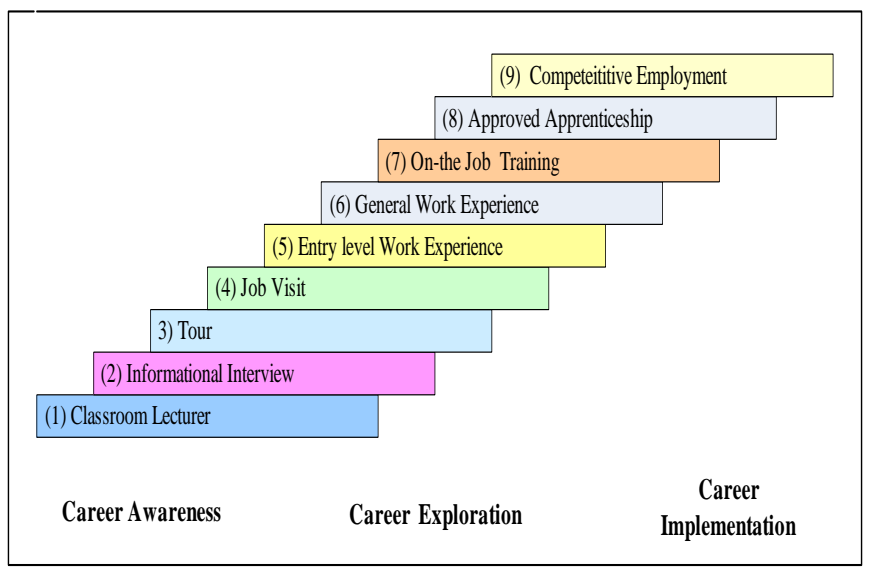

Fig. 1. Continuum of Work-Based Learning Experiences. [11]

The levels above also show the education levels, and the desired career levels, starting from: (1) career awareness, which is giving an awareness of career; (2) career exploration; and (3) career implementation. The higher the level, the higher the participant's involvement.

WBL includes a series of learning activities outside of the traditional learning confined by classroom walls. Variability of WBL consists of job shadowing, service learning, internship, and apprenticeship. WBL is a Career and Technical Education (CTE) which provides valuable experience in the world of work. The approaches used in WBL includes learning experience which creates a meaningful structure and beneficial for students so they can realize it through the participation in their experience.

WBL facilitates the students and educational institutions to be able to prepare the students as good as a company employee. Their activities in learning are through the involvement of th real activities. WBL can train independence, problem-solving, knowledge application, confidence, and motivates the students to keep learning. In WBL executions, the students learn independently, learning with others on how to solve a problem, how to apply an academic and technical knowledge in workplace, so they realize they have to keep learning to improve their career [11].

Learning process in WBL context lead to the competence achievement that has to be mastered by the students in cognitive, affective, and conative realm. Several relevant concepts that can become a guide in including WBL elements are learning at work, which is a learning at workplace, learning through work, which is a learning through or while working, learning for work, by doing something better, and learning from work, by using the working experience.

All of these experiences at workplace could create a performance if a learning process happened. Kreitner and Kinicki [4] explained it in the following concept: 


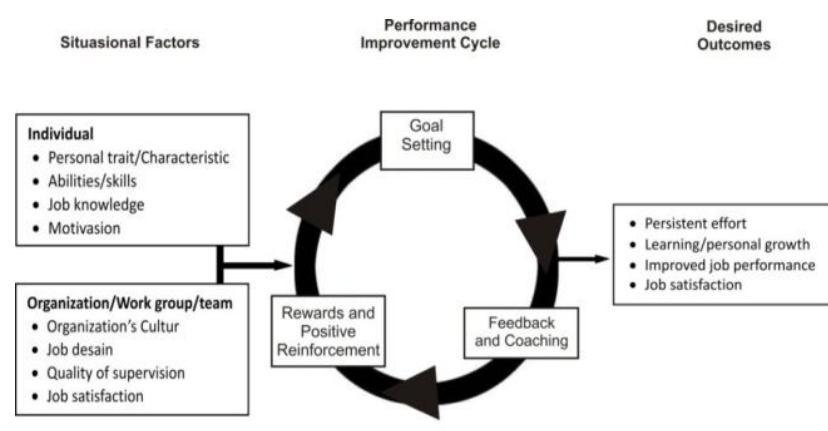

Fig 2. Improving Individual Job Performance: A Continuous Process [4]

The figure 2 above informs us that the individual performance improvement process is affected by two large factors: the individual and organizational factors. Individual factors include the personal characteristics, habits, working knowledges, and motivations. While organizational factors include the organizational culture, working design, and supervisor quality. Meanwhile, it is shown that acquisition or the desired outcome gain can be manifested through the cyclical process. This cycle has components consisting of goal setting, feedback and coaching, and also reward and positive reinforcement.

Explained further by Kreitner Kinicki [4], goal-setting can improve the outcome produced. The result of the survey done by Franklin Covey stated that in the US, 56\% of workers don't really understand what the most important goal of organization, and $81 \%$ of them don't have a clear definition of goals. This represents one unproductive situation. According to the experts, the forgotten thing in this case is the "line of sight". The workers with the clear understanding of "line of sight", understand the strategy and goal of organization, will recognize what they have to do.

\section{b. Effectiveness of Work-Based Learning in Building Employability Skills}

Employability Skill aspect is a group of skills needed to enter the world of work or for career development in the workplace. Robinson [9] stated: "Employability skills are those basic skills necessary for getting, keeping, and doing well on the job."

Employability skills are skills, behaviors, and actions that enable workers relate with other workers, including with the supervisor, dare to voice the opinion and contribute in important decisions. Unlike working or technical skills, employability skills is more common and natural than a specific work on all kinds of industries, company size, and level of work when the worker starts entering until in the senior position.

The focus of employability skills, according to the study done by Kokom Komariah [3] to level 3 Diplo ma college students in culinary program that tested the application of WBL in hotel industry, showed the indicators of trainable employability skills such as: (1) working dependability; (2) cooperative ability; (3) judgment ability; (4) initiative; (5) personality; and (6) ability to react to criticisms and suggestions.
The study result shows the aspect of employability skills or the readiness to enter the world of work. Based on the result of data analysis, the "before" data has mean of 18.62 , median of 19.00, and mode of 15.00, skewness of -0.080 , while the "after" data showed the mean of 25.05, median of 25.500 , mode of 26.00 , and skewness of -0.520 . Both data groups showed the smaller mean position compared to median and mode, and both showed the negative skewness, which means the employability skills of the students before the activity is already good enough and above the average, and even better after the activity. Further explanation is in the table below:

Table.1. Employability Skills Before and After Doing the Work-based Learning

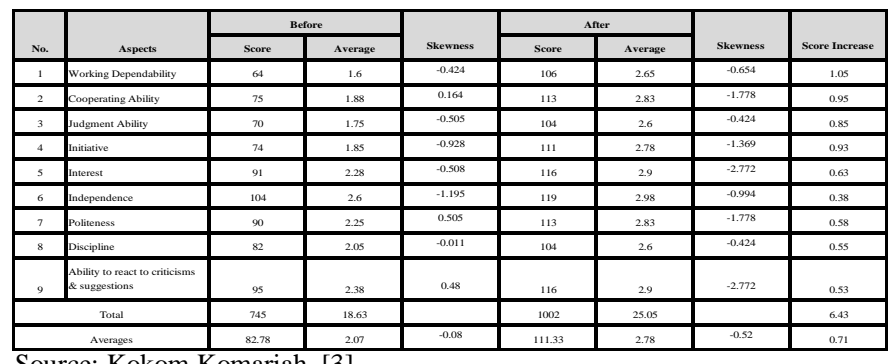

Based on this data, it is proved that WBL is able to improve the college students' employability skills, from good into better. The highest improvement is from the working dependability, and a relatively low improvement is from the independence. This is acceptable because the independence score before the activity is already has a high value.

\section{Conclusion}

a. Work-Based Learning is highly relevant to realize the mission of vocational education, because WBL process brings the students closely with the work, so the students acquire knowledges, skills, and behaviors for the career purpose and other life roles in the future.

b. Work-Based Learning is able to improve the employability skills of the students, which includes working dependability, cooperative ability, judgment ability, initiative, personality, and the ability to react to criticisms and suggestions. This learning model is proved to be able to improve the aspects of employability skills of the students from good into better on each of its indicators.

\section{Reference:}

[1] .--------, (2002). Work-based learning guide 2002. Des Moines: Developed in Cooperation with Iowa Association of Bussiness and Industry Foundation.

[2] Cunningham I, Dawes, G \& Bennett, B. The hand book of work based learning. England: Gower Publishing Limited Worth Publishing Company, 2004

[3] Kokom Komariah. Pengembangan Model Pembelajaran pengolahan Makanan dalam Konteks Work-based learning di Industri Hotel bagi Mahasiswa Program Diploma III. Disertasi. Yogyakarta:Program Pascasarjana Universitas Negeri Yogyakarta, 2013

[4] Kreitner,R, Kinicki, A. Organizational Behavior. New York: The McGraw-Hill, 2008 
[5] Medhat, S (2008). Final report. the progress of wbl strategies in higher education engineering programmers. Education.uts http://www.projects.: edu.au/RWLA/RWLA Papers/8206.doc

[6] Robinson. J. The work place. Volume 1 Alabama Cooperative Extension System, ( September 15, 2000. 